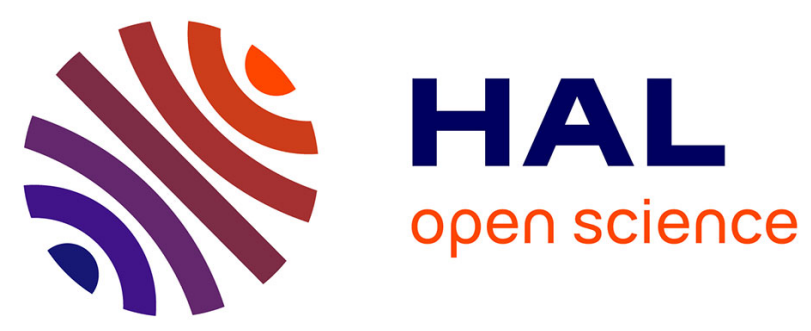

\title{
Lack of a Clinically Significant Pharmacokinetic Interaction between Etravirine and Raltegravir Using an Original Approach Based on Drug Metabolism, Protein Binding, and Penetration in Seminal Fluid: A Pharmacokinetic Substudy of the ANRS-163 ETRAL Study
}

Minh Patrick Lê, Marc Antoine Valantin, Lambert Assoumou, Cathia Soulié, Soizic Le Mestre, Laurence Weiss, Yazdan Yazdanpanah, Jean Michel Molina, Olivier Bouchaud, Francois Raffi, et al.

\section{To cite this version:}

Minh Patrick Lê, Marc Antoine Valantin, Lambert Assoumou, Cathia Soulié, Soizic Le Mestre, et al.. Lack of a Clinically Significant Pharmacokinetic Interaction between Etravirine and Raltegravir Using an Original Approach Based on Drug Metabolism, Protein Binding, and Penetration in Seminal Fluid: A Pharmacokinetic Substudy of the ANRS-163 ETRAL Study. Pharmacotherapy: The Journal of Human Pharmacology and Drug Therapy, 2019, 39 (4), pp.514-520. 10.1002/phar.2242 . hal02442744

\author{
HAL Id: hal-02442744 \\ https://hal.science/hal-02442744
}

Submitted on 16 Jan 2020

HAL is a multi-disciplinary open access archive for the deposit and dissemination of scientific research documents, whether they are published or not. The documents may come from teaching and research institutions in France or abroad, or from public or private research centers.
L'archive ouverte pluridisciplinaire HAL, est destinée au dépôt et à la diffusion de documents scientifiques de niveau recherche, publiés ou non, émanant des établissements d'enseignement et de recherche français ou étrangers, des laboratoires publics ou privés. 
Minh Patrick Lê, ${ }^{1,2, *}$ (D) Marc-Antoine Valantin, ${ }^{3,4}$ Lambert Assoumou, ${ }^{4}$ Cathia Soulie, ${ }^{5}$ Soizic Le Mestre, ${ }^{6}$ Laurence Weiss, ${ }^{7}$ Yazdan Yazdanpanah, ${ }^{1,8}$ Jean-Michel Molina, ${ }^{9}$ Olivier Bouchaud, ${ }^{10}$ François Raffi, ${ }^{11}$ Jacques Reynes, ${ }^{12,13}$ Vincent Calvez, ${ }^{5}$ Anne-Geneviève Marcelin, ${ }^{5}$ Dominique Costagliola, ${ }^{4}$ Christine Katlama, ${ }^{3,4}$ and Gilles Peytavin, ${ }^{1,2}$ ANRS-163 ETRAL study group ${ }^{\dagger}$ ${ }^{1}$ IAME, UMR 1137, Sorbonne Paris Cité and INSERM, Université Paris Diderot, Paris, France; ${ }^{2}$ Laboratoire de Pharmacologie-Toxicologie, AP-HP, Hôpital Bichat-Claude Bernard, Paris, France; ${ }^{3}$ Service de Maladies Infectieuses et Tropicales, AP-HP, Hôpital Pitié-Salpêtrière, Paris, France; ${ }^{4}$ INSERM, Institut Pierre Louis d'Epidémiologie et de Santé Publique (iPLESP UMRS 1136), Sorbonne Université, UPMC Univ Paris 06, Paris, France; ${ }^{5}$ Laboratoire de Virologie, INSERM, Institut Pierre Louis d'Epidémiologie et de Santé Publique (iPLESP), AP-HP, Hôpital Pitié Salpêtrière, Sorbonne Université, Paris, France; ${ }^{6}$ France Recherche Nord \& Sud SIDA-HIV Hépatites (ANRS), Paris, France; ${ }^{7}$ Service d'Immunologie Clinique, AP-HP, Hôpital Européen Georges Pompidou, Paris, France; ${ }^{8}$ Service de Maladies Infectieuses et Tropicales, AP-HP, Hôpital Bichat-Claude Bernard, Paris, France;

${ }^{9}$ Service de Maladies Infectieuses et Tropicales, INSERM U941, AP-HP, Hôpital Saint Louis, Université Denis

Diderot Paris VII, Paris, France; ${ }^{10}$ Service de Maladies Infectieuses et Tropicales, AP-HP, Hôpital Avicenne, Bobigny, France; ${ }^{11}$ Department of Infectious Diseases, Hotel-Dieu Hospital - INSERM CIC 1413, Nantes University Hospital, Nantes, France; ${ }^{12}$ Service de Maladies Infectieuses et Tropicales, CHU Montpellier, Montpellier, France;

${ }^{13}$ INSERM U1175, IRD UMI 233, University of Montpellier, Montpellier, France

Study Oвjective The ANRS163-ETRAL study showed that etravirine $200 \mathrm{mg} /$ raltegravir $400 \mathrm{mg}$ twicedaily dual therapy was highly effective in the treatment of human immunodeficiency virus (HIV)infected patients older than 45 years, with virologic and therapeutic success rates at week 48 of $99.4 \%$ and $94.5 \%$, respectively. The objective of this study was to determine whether a clinically

\footnotetext{
${ }^{\dagger}$ Members are listed in the Acknowledgments.

PI statement: The authors confirm that the principal investigator for this research was Christine Katlama and that she had direct clinical responsibility for the patients included in this study.

This trial was sponsored by the Agence Nationale de Recherche sur le SIDA et les hépatites virales (ANRS) and was conducted with the support of Merck Sharp \& Dohme and Janssen-Cilag.

Conflict of interest: Minh Lê has received travel grants from Bristol-Myers Squibb, ViiV Healthcare, and Janssen. François Raffi has received research funding or honoraria from or acted as a consultant for Abbvie, Bristol-Myers Squibb, Gilead Sciences, Janssen, MSD, ViiV Healthcare. Jean-Michel Molina has participated on advisory boards for Gilead, Merck, Janssen, ViiV, Bristol-Myers Squibb, and Teva, and his institution has received grants from Merck and Gilead. Gilles Peytavin has received travel grants, consultancy fees, honoraria, and study grants from various pharmaceutical companies, including Bristol-Myers Squibb, Gilead Sciences, Janssen, Merck, and ViiV Healthcare. None of the other authors have any conflicts of interest to declare.

*Address for correspondence: Minh Patrick Lê, Laboratoire de Pharmacologie-Toxicologie, AP-HP, Hôpital Bichat-Claude Bernard, 46 rue Henri Huchard, 75018 Paris, France; e-mail: minh.le@aphp.fr.

(C) 2019 Pharmacotherapy Publications, Inc.
} 
significant pharmacokinetic interaction between etravirine and raltegravir exists by assessing steadystate total and unbound etravirine, raltegravir, and inactive raltegravir-glucuronide concentrations 12 hours after last intake $\left(\mathrm{C}_{12 \mathrm{~h}}\right)$ in blood plasma (BP) and seminal plasma (SP).

DESIGN Pharmacokinetic analysis of data from the ANRS163-ETRAL study.

PATIENTS One hundred forty-six HIV-1-infected patients (of the 165 patients included in the ANRS163 ETRAL study) who were receiving etravirine $200 \mathrm{mg}$ and raltegravir $400 \mathrm{mg}$ twice daily.

Measurements and Main Results Blood was collected from all 146 patients at weeks 2-4, 12, 24, and 48, and semen was collected from 21 patients at week 48. The extent of BP and SP protein binding was determined by using ultrafiltration assay. Total and unbound etravirine, raltegravir, and raltegravir-glucuronide $\mathrm{C}_{12 \mathrm{~h}}$ were determined by ultra high performance liquid chromatography coupled with tandem mass spectrometry and interpreted by using the in vitro calculated protein-bound $95 \%$ inhibitory concentration $\left(\mathrm{PBIC}_{95}\right.$ ) for wild-type (WT) HIV: etravirine $(116 \mathrm{ng} / \mathrm{ml}$ ) and raltegravir (15 ng/ml). Median (interquartile range [IQR]) total BP etravirine $C_{12 \mathrm{~h}}(536 \mathrm{ng} / \mathrm{ml}$ [376-719]) and raltegravir (278 $\mathrm{ng} / \mathrm{ml} \mathrm{[97-690])} \mathrm{were} \mathrm{adequate} \mathrm{in} 99 \%$ and $96 \%$ of patients, respectively. Median (IQR) SP:BP $C_{12 h}$ ratio and $\mathrm{BP}$ unbound fraction were etravirine $0.3(0.2-0.5)$ and $<1 \%$, respectively, raltegravir 1.8 (1.3-3.3) and 12\%, respectively, and raltegravir-glucuronide 12.0 (6.5-17.7) and $>99 \%$, respectively. The BP raltegravir metabolic ratio (raltegravir glucuronide:raltegravir ratio) was 1.7, suggesting only weak induction of raltegravir glucuronidation by etravirine. Only three patients had etravirine and raltegravir $\mathrm{C}_{12 \mathrm{~h}}<$ PBIC $_{95}$ simultaneously.

CONCLUSION No clinically significant pharmacokinetic interaction between etravirine and raltegravir was detected. Total etravirine and raltegravir BP concentrations were adequate in most patients, favoring virologic efficacy and confirming good treatment adherence ( $>95 \%)$, despite twice-daily administration. The long half-life of etravirine and higher unbound fraction SP of raltegravir (57\%) ensured adequate concentrations of dual therapy in genital compartments. Our results indicate that etravirine and raltegravir have good, complementary pharmacokinetic profiles, suggesting that they could be used in a dual-treatment strategy.

Key Words dual therapy, antiretroviral, etravirine, raltegravir, pharmacokinetics, seminal fluid, interaction.

(Pharmacotherapy 2019;39(4):514-520) doi: 10.1002/phar.2242

\section{Introduction}

There is growing clinical interest in the evaluation of new antiretroviral strategies sparing nucleoside analogs (nucleoside/nucleotide reverse transcriptase inhibitors [NRTIs]) and protease inhibitors (PIs), particularly in aging populations with a long cumulative exposure to antiretroviral drugs. NRTIs and PIs have been associated with cumulative long-term toxicity, with bone and renal disorders reported in patients taking tenofovir and an increase in cardiovascular risk for patients taking PIs. ${ }^{1}$ The aging of patients with human immunodeficiency virus (HIV) infection is now a major concern, given the increase in polypharmacy prescriptions due to the higher rates of comorbidities such as bone demineralization, cardiovascular and cerebrovascular disease, diabetes mellitus, and renal dysfunction. ${ }^{2}$ The increase in polypharmacy prescription rates raises questions about drug-drug interactions (DDIs), particularly for antihypertensive agents, anticoagulants, statins, and antiepileptic drugs that are cytochrome P450 (CYP) or P-glycoprotein (P-gp) substrates. Strategies for long-term virologic suppressive therapies with less DDI potential are required for patients with comorbid conditions. These alternative strategies must maintain HIV suppression, in all compartments, while minimizing the occurrence of long-term clinical and metabolic complications.

The results of a pilot study evaluating a dualtreatment strategy based on the twice-daily administration of etravirine/raltegravir suggested that such NRTI/PI-sparing strategies were a potential option for maintaining virologic suppression at week 48 (W48) while minimizing DDIs. ${ }^{3}$ Etravirine, a nonnucleoside analog (nonnucloside reverse transcriptase inhibitor [NNRTI]), and raltegravir, an integrase inhibitor, have good efficacy profiles. Etravirine remains active against viruses harboring single K103N mutations (signature of first-generation 
NNRTIs), ${ }^{4}$ and raltegravir trended to be superior to efavirenz after 5 years of treatment in the STARTMRK study. ${ }^{5}$ Both compounds have good reported safety profiles, reducing the risk of long-term toxicity. ${ }^{5}$ Contrary interpretations of a DDI between etravirine and raltegravir are reported throughout the literature, although limited data are available for this dual regimen. ${ }^{7-10}$

The ANRS-163 ETRAL trial (ClinicalTrials.gov identifier NCT02212379) was a 96-week, international, multicenter, open phase II trial. Its principal objective was to evaluate, at $\mathrm{W} 48$, the capacity of the etravirine/raltegravir combination to maintain virologic success in HIV-1-infected patients of at least 45 years of age with suppressed viremia (plasma HIV RNA < 50 copies/ $\mathrm{ml}$ ) switching from a boosted PI-containing regimen. ${ }^{11}$ This strategy was found to be highly effective and safe in these patients, with virologic and therapeutic success rates of $99.4 \%$ and $94.5 \%$, respectively, at $\mathrm{W} 48$.

Etravirine is mainly metabolized by CYP3A4, CYP2C9, and CYP2C19 and is an inducer of CYP3A4 and inhibitor of CYP2C9 and CYP $2 \mathrm{C} 19,{ }^{10}$ whereas raltegravir is mainly metabolized by uridine diphosphoglucuronosyltransferase (UGT) 1Al, without the involvement of CYP, and does not inhibit P-gp-mediated transport. However, considerable inter- and intraindividual variability has been observed in the pharmacokinetics of raltegravir. ${ }^{10}$ Thus, no DDI was expected, justifying the use of this combination of an NNRTI and integrase inhibitor. Raltegravir is the only integrase inhibitor for which no clinically significant drug interaction has been reported with CYP3A inducers or inhibitors except for rifampin. ${ }^{10}$ The other dual regimen based on approved NNRTIs and integrase inhibitors is the combination of dolutegravir plus rilpivirine $(50+25 \mathrm{mg}$ every $24 \mathrm{hrs})$. Indeed, dolutegravir is metabolized by CYP3A4, and its plasma exposure is significantly decreased when coadministrated with etravirine. ${ }^{12}$ The use of the combination of elvitegravir/cobicistat with etravirine is also not recommended because the elvitegravir/cobicistat combination mainly undergoes metabolism through the CYP3A4 pathway. ${ }^{10}$ The metabolic profile of etravirine suggests that its combination with raltegravir might be compatible, but caution is advised concerning other concomitant medications and the potential risk of DDIs. In the ANRS-163 ETRAL study, patients' prescriptions were analyzed for DDIs based on the information provided on the product information labels for etravirine and raltegravir. ${ }^{10}$
In this pharmacokinetic substudy, the objective was to assess steady-state total and unbound concentrations 12 hours after last intake $\left(C_{12 h}\right)$ of etravirine, raltegravir, and raltegravir glucuronide, in both blood and seminal plasma from HIV-1-infected patients receiving etravirine $200 \mathrm{mg}$ twice daily and raltegravir $400 \mathrm{mg}$ twice daily to determine whether a clinically significant pharmacokinetic interaction between etravirine and raltegravir exists and to support the efficacy and safety results of the ANRS-163 ETRAL study.

\section{Methods}

In this pharmacokinetic analysis, the eligibility criteria were those of the ANRS-163 ETRAL trial $^{11}$ : HIV-1 infection; age $>45$ years; naïve for integrase inhibitors and etravirine; $>6$ months of stable antiretroviral therapy including a boosted PI, whatever the number of combined drugs; plasma HIV RNA $\leq 50$ copies/ml during the last 24 months, and no DDIs between concomitant medications and etravirine or raltegravir, based on their respective product information. ${ }^{10}$ Written informed consent for this pharmacokinetic substudy, including consent for collection of semen samples, was obtained with participation to the main study. The study protocol was reviewed and approved by the local ethics committees and was conducted in accordance with the Declaration of Helsinki.

Blood samples were collected at W2-4, W12, W24, and W48 $12 \pm 2$ hours after the last intake. Semen samples were collected at W48 within the hour after the blood sampling. Blood and seminal plasma samples were immediately centrifuged, and the respective samples were stored at $-80^{\circ} \mathrm{C}$. All patients were considered to be at steady state by W2 according to the respective elimination half-lives of etravirine (30-40 hrs) and raltegravir ( $9 \mathrm{hrs}) .{ }^{10}$ Binding to blood and seminal plasma proteins was assessed for all samples in an ultrafiltration assay (Centrifree; Millipore, Molsheim, France) of 400- $\mu 1$ samples $\left(2000 \mathrm{~g}\right.$ for $30 \mathrm{~min}$ at $\left.25^{\circ} \mathrm{C}\right){ }^{13,14}$ Blood and seminal plasma concentrations of etravirine, raltegravir, and raltegravir glucuronide were determined by ultra high performance liquid chromatography coupled with tandem mass spectrometry (UPLC-MS/MS; Waters Acquity UPLC-TQD, Milford, MA). ${ }^{15}$ The limit of quantification was $<5 \mathrm{ng} / \mathrm{ml}$ for all assays, and interpretation was based on the corresponding in vitro protein-adjusted $95 \%$ inhibitory 
concentration $\left(\mathrm{PBIC}_{95}\right.$ ) for wild-type (WT) HIV1: $116 \mathrm{ng} / \mathrm{ml}^{16}$ for etravirine and $15 \mathrm{ng} / \mathrm{ml}$ for raltegravir. ${ }^{17}$ Etravirine and raltegravir $C_{12 \mathrm{~h}}$ were considered to be adequate if above the respective $\mathrm{PBIC}_{95}$. Metabolic ratio was determined as the raltegravir glucuronide:raltegravir ratio.

\section{Statistical Analysis}

Results are presented as median (interquartile range $[\mathrm{IQR}]$ ) values. Mann-Whitney and Kruskal-Wallis tests were used for statistical comparisons between the four sample collection visits. No correction for multiple comparisons was performed, and a p value $<0.05$ was considered to indicate a statistically significant difference.

\section{Results}

We included 146 of the 165 patients from the ANRS-163 ETRAL study in this pharmacokinetic analysis. Baseline characteristics of the 146 patients are presented in Table 1. Median age was 52 (IQR $48-58$ ) years, $71 \%$ were male, $75 \%$ were Caucasian and 15\% were from sub-Saharan Africa, and median duration of viremia suppression was 6.9 (IQR 3.4-9.3) years.

For the 504 blood samples collected from the 146 patients during 48 weeks (four visits), the median total blood plasma $C_{12 \mathrm{~h}}$ values of etravirine and raltegravir were $536 \mathrm{ng} / \mathrm{ml}$ (IQR 376719) and $278 \mathrm{ng} / \mathrm{ml}$ (IQR 97-690), respectively. Total blood plasma $C_{12 \mathrm{~h}}$ values are presented for the four visits in Table 2 . The $\mathrm{C}_{12 \mathrm{~h}}$ of etravirine, raltegravir, and raltegravir glucuronide did not significantly differ between visits. Overall, blood plasma concentrations of etravirine and raltegravir were above the corresponding $\mathrm{PBIC}_{95}$ in 99\% for etravirine and 96\% for raltegravir, with only three patients with both etravirine and raltegravir blood plasma $\mathrm{Cl}_{2 \mathrm{~h}}<\mathrm{PBIC}_{95}$. The median fractions of the drugs remaining unbound in blood plasma were $<1 \%$ for etravirine, $12 \%$ for raltegravir (IQR $10-15 \%$ ) and $>99 \%$ for raltegravir glucuronide (IQR 91-100\%), with no significant changes observed during the study period. Low median interpatient and interoccasion variabilities were recorded for total etravirine blood plasma $\mathrm{C}_{12 \mathrm{~h}}$ of $45 \%$ and $24 \%$, respectively, in contrast with total raltegravir blood plasma $\mathrm{C}_{12 \mathrm{~h}}$ of $166 \%$ and $91 \%$, respectively. Total blood plasma metabolic ratio (raltegravir glucuronide: raltegravir $\mathrm{C}_{12 \mathrm{~h}}$ ) was $1.7(1.1-2.8)$ and remained stable over time (Table 2). Finally, 21 semen samples were collected from 21 patients. Median
Table 1. Baseline Characteristics of the Study Patients

\begin{tabular}{lc}
\hline Characteristic & Data $(\mathrm{n}=146)$ \\
\hline Age (yrs) & $52(48-58)$ \\
Male sex & $103(71 \%)$ \\
Race-ethnicity & $109(75 \%)$ \\
$\quad$ Caucasian & $22(15 \%)$ \\
$\quad$ Sub-Saharan African & $15(10 \%)$ \\
Other & $14(10 \%)$ \\
HCV coinfection & $6.9(3.4-9.3)$ \\
Duration of suppressed & \\
plasma HIV-RNA (< 50 copies/ml; yrs) & $4.8(2.7-7.4)$ \\
Duration of last ART (yrs) & $107(73 \%)$ \\
Last ART once-daily dosing & \\
Last ART regimen & $95(65 \%)$ \\
2 NRTIs + PI/r & $10(7 \%)$ \\
$\quad$ NNRTI + PI/r & $31(21 \%)$ \\
PI/r & $10(7 \%)$ \\
$\quad$ Other &
\end{tabular}

Data are no. (\%) of patients or median (interquartile range) values. ART $=$ antiretroviral treatment; $\mathrm{HCV}=$ hepatitis $\mathrm{C}$ virus; $\mathrm{HIV}=$ human immunodeficiency virus; $\quad \mathrm{NNRTI}=$ nonnucloside reverse transcriptase inhibitor; $\quad \mathrm{NRTI}=$ nucleoside/nucleotide reverse transcriptase inhibitor; $\mathrm{PI} / \mathrm{r}=$ ritonavir-boosted protease inhibitor.

seminal:blood plasma $C_{12 \mathrm{~h}}$ ratios were $0.3(0.2-$ $0.5)$ for total etravirine, $1.8(1.3-3.3)$ for total raltegravir, 12.0 (6.5-17.7) for unbound raltegravir, 5.7 (2.0-11.6) for total raltegravir glucuronide, and 2.4 (0.8-4.1) for unbound raltegravir glucuronide (geometric means $[95 \%$ confidence intervals] data are presented in Figure 1). The seminal:blood plasma ratio of unbound etravirine could not be determined because all unbound concentrations of etravirine were below the limit of quantification.

\section{Discussion}

To our knowledge, this is the first study to determine whether an interaction exists between etravirine and raltegravir in a dual maintenance antiretroviral regimen without any other interfering antiretroviral agent. In this study of HIV1-infected patients ( $>45$ years of age) with suppressed viremia switching from a boosted PI-containing regimen to dual therapy, etravirine and raltegravir blood plasma $C_{12 \mathrm{~h}}$ were consistent with findings published separately and the information provided with the products. As expected, no evident DDI between etravirine and raltegravir was reported with no significant difference in etravirine and raltegravir $C_{12 \mathrm{~h}}$ between the four sample collection visits (Table 2). Moreover, these results are consistent with published data from healthy subjects. ${ }^{9}$ Most patients had adequate blood plasma $\mathrm{C}_{12 \mathrm{~h}}$ for etravirine $(<1 \%$ of patients with $\left.\mathrm{C}_{12 \mathrm{~h}}<\mathrm{PBIC}_{95}\right)$ and raltegravir 
Table 2. Total and Unbound Blood and Seminal Plasma Trough Concentrations of Etravirine, Raltegravir, and Raltegravir Glucuronide, and Total and Unbound Metabolic Ratios

\begin{tabular}{|c|c|c|c|c|c|}
\hline \multirow[b]{2}{*}{ Parameter } & \multicolumn{4}{|l|}{ Study Visit } & \multirow[b]{2}{*}{$\mathrm{p}$ Value $^{\mathrm{a}}$} \\
\hline & Weeks 2-4 & Week 12 & Week 24 & Week 48 & \\
\hline $\begin{array}{l}\text { No. of blood samples } \\
\text { (one sample/patient) }\end{array}$ & 125 & 138 & 138 & 103 & \\
\hline Total etravirine $C_{12 h}(\mathrm{ng} / \mathrm{ml})$ & $507(364-733)$ & $538(373-710)$ & $532(373-693)$ & $586(434-819)$ & 0.0691 \\
\hline Unbound etravirine $C_{12 \mathrm{~h}}(\mathrm{ng} / \mathrm{ml})$ & $<5(\mathrm{NA})$ & $<5(\mathrm{NA})$ & $<5(\mathrm{NA})$ & $<5(\mathrm{NA})$ & \\
\hline Total raltegravir $\mathrm{C}_{12 \mathrm{~h}}(\mathrm{ng} / \mathrm{ml})$ & $278(97-599)$ & $352(97-741)$ & $223(83-834)$ & $267(111-737)$ & 0.8991 \\
\hline Unbound raltegravir $C_{12 \mathrm{~h}}(\mathrm{ng} / \mathrm{ml})$ & $41(18-82)$ & $45(13-93)$ & $30(11-109)$ & $30(13-83)$ & 0.4342 \\
\hline $\begin{array}{l}\text { Total raltegravir } \\
\text { glucuronide } C_{12 \mathrm{~h}}(\mathrm{ng} / \mathrm{ml})\end{array}$ & $544(246-1297)$ & $541(227-1355)$ & $521(196-1338)$ & $535(240-1018)$ & 0.7991 \\
\hline $\begin{array}{l}\text { Unbound raltegravir } \\
\text { glucuronide } \mathrm{C}_{12 \mathrm{~h}}(\mathrm{ng} / \mathrm{ml})\end{array}$ & $589(277-1446)$ & $614(230-1612)$ & $666(253-1390)$ & $519(242-1077)$ & 0.7183 \\
\hline Total raltegravir metabolic ratio & $2.0(1.1-3.1)$ & $1.6(1.1-2.8)$ & $1.6(1.0-3.0)$ & $1.6(1.0-2.3)$ & 0.3311 \\
\hline Unbound raltegravir metabolic ratio & $15.9(9.6-26.2)$ & $15.0(10.4-23.6)$ & $16.9(10.9-26.7)$ & $16.7(9.9-25.9)$ & 0.7904 \\
\hline $\begin{array}{l}\text { No. of seminal samples } \\
\text { (one sample/patient) }\end{array}$ & & & & 21 & \\
\hline Total etravirine $C_{12 \mathrm{~h}}(\mathrm{ng} / \mathrm{ml})$ & & & & $122(98-229)$ & \\
\hline Unbound etravirine $C_{12 h}(n g / m l)$ & & & & $<5$ (NA) & \\
\hline Total raltegravir $C_{12 \mathrm{~h}}(\mathrm{ng} / \mathrm{ml})$ & & & & $560(348-798)$ & \\
\hline Unbound raltegravir $C_{12 \mathrm{~h}}(\mathrm{ng} / \mathrm{ml})$ & & & & $397(217-512)$ & \\
\hline $\begin{array}{l}\text { Total raltegravir } \\
\text { glucuronide } C_{12 \mathrm{~h}}(\mathrm{ng} / \mathrm{ml})\end{array}$ & & & & $2931(1070-5908)$ & \\
\hline $\begin{array}{l}\text { Unbound raltegravir } \\
\text { glucuronide } \mathrm{C}_{12 \mathrm{~h}}(\mathrm{ng} / \mathrm{ml})\end{array}$ & & & & $1359(429-2411)$ & \\
\hline
\end{tabular}

Data are median (interquartile range) values.

$\mathrm{C}_{12}=12$ hours after last intake; NA = not applicable.

${ }^{a}$ Statistical analysis was based on nonparametric Kruskal-Wallis tests, with significance defined as $\mathrm{p}<0.05$.

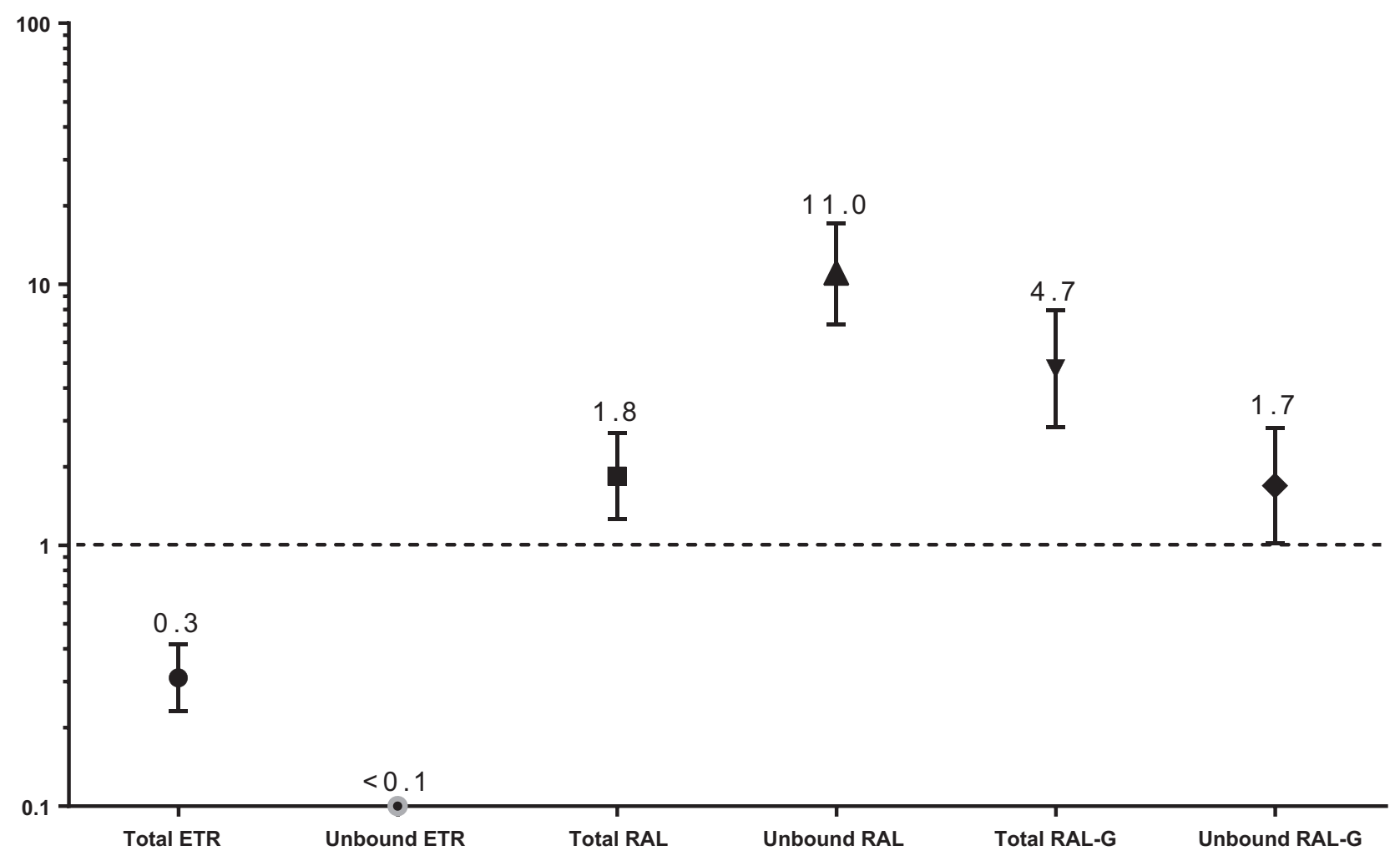

Figure 1. Seminal/blood plasma ratios for total and unbound etravirine, raltegravir, and raltegravir glucuronide at week 48 $(n=21)$. Symbols and whiskers show geometric means and $95 \%$ confidence intervals. Ratios $<1$ are interpreted as moderate seminal penetration, and ratios $>1$ as good seminal penetration. 
( $<5 \%$ of patients with $\mathrm{C}_{12 \mathrm{~h}}<\mathrm{PBIC}_{95}$ ), consistent with the observed high virologic efficacy at W48 and confirming excellent treatment adherence (> 95\%), despite twice-daily dosing (only three patients had both etravirine and raltegravir $C_{12 \mathrm{~h}}$ $<$ PBIC $_{95}$ ), as most patients (73\%) were taking a once-daily antiretroviral drug regimen before switching.

Surprisingly, despite the lack of an expected DDI with etravirine, the total metabolic ratio of raltegravir glucuronide/raltegravir appeared to be lower than that reported in the Belkhir et al. ${ }^{18}$ study, regardless of the UGT1Al polymorphism. To the contrary, our total metabolic ratio results were consistent with previous results in healthy volunteers.9, 19 Nevertheless, the decrease in metabolic ratio might also be explained by higher elimination of the raltegravir glucuronide due to an induction of the expression of genes coding for efflux transporters. $^{20}$

One key concern related to the less-drug antiretroviral drug strategies is the penetration of the drugs into deep compartments. Moderate penetration of etravirine into the seminal compartment was observed in our patients (Figure 1), consistent with previous results (including patients receiving a ritonavir-boosted PI-containing regimen). ${ }^{21,} 22$ This moderate penetration is probably due to its high plasma protein binding, compensated by its long elimination half-life and low variability. ${ }^{10}$ In contrast, raltegravir penetration into the seminal compartment was reported to be lower, but also with a lower variability, than in previous studies, which might be mechanistically explained by the induction of the efflux of raltegravir from the semen. ${ }^{22-27}$

Raltegravir is transported by $\mathrm{P}-\mathrm{gp} / \mathrm{ABCB} 1$ but also by BCRP/ABCG $2,{ }^{27}$ which are both highly expressed in epididymis ${ }^{28}$ and induced by etravirine. ${ }^{20,} 29$ Etravirine, after a single dose, was also reported to be a potent inhibitor of BCRP/ ABCG2 and not an inhibitor of P-gp/ABCB1. ${ }^{20,29}$ Our results at steady state suggest that the induction of both P-gp/ABCB1 and BCRP/ABCG2 might be of greater impact than the sole inhibition of BCRP/ABCG2. Despite the probable interaction through the efflux transporters, the seminal concentration of raltegravir remained above the PBIC $_{95}$, suggesting sufficient penetration in this compartment. The mechanistic hypothesis of the DDI remains difficult to assess probably due to the erratic pharmacokinetic profile of raltegravir and the paucity of data concerning the seminal penetration of raltegravir (particularly raltegravir glucuronide and the unbound fraction of both raltegravir and its glucuronide metabolite) without coadministration of compounds such as ritonavirboosted PIs or NNRTIs that might also impact efflux transporters. Finally, the inducer potential of etravirine on efflux transporters raises the question of the DDI with concomitant medications, which might be underestimated, and their clinical relevance depending on their respective therapeutic indexes.

The main limitations of our study would be that the study was not designed for a bioequivalence assessment with sampling allowing determination of both maximum concentration and area under the concentration-time curve from time 0 to 24 hours. Also, cervicovaginal secretions were not obtained since the study was a multicenter study, and the sampling method was critical.

\section{Conclusion}

In this ANRS-163 ETRAL pharmacokinetic substudy, no clinically significant pharmacokinetic interaction between etravirine and raltegravir was detected. Total and unbound blood plasma concentrations of etravirine, raltegravir, and raltegravir glucuronide remained stable over the study period. Overall, the etravirine/raltegravir dual regimen seems to provide adequate blood plasma exposure and seminal penetration in accordance with the high virologic and therapeutic success rates of $99.4 \%$ and $94.5 \%$, respectively. Given the excellent results for both adherence and virologic data obtained for the blood and seminal compartments, our results indicate that etravirine and raltegravir have good, complementary pharmacokinetic profiles, suggesting that they could be used in a dualtreatment strategy.

\section{Acknowledgments}

The authors thank all the participating patients and the study nurses at the clinical sites. Study investigators and participating centers are as follows: Claudine Duvivier (AP-HP, Hôpital Necker, Paris), Cécile Goujard (AP-HP, Hôpital Bicêtre, Kremlin-Bicêtre), Vincent Jeantils (AP-HP, Hôpital Jean Verdier, Bondy), Olivier Bouchaud (AP-HP, Hôpital Avicenne, Bobigny), Laurence Weiss (AP-HP, AP-HP, Hôpital Européen Georges Pompidou, Paris), Dominique Salmon (AP-HP, Hôpital Cochin, Paris), Marc-Antoine Valantin (AP-HP, Hôpital Pitié Salpêtrière, Paris), Anne Simon (AP-HP, Hôpital Pitié Salpêtrière, Paris), Jean Michel Molina, Nathalie Colin de Verdière (AP-HP, Hôpital Saint Louis, Paris), Philippe Morlat (Saint André, Bordeaux), Isabelle Poizot-Martin (AP-HM, Hôpital Sainte-Marguerite, Marseille), Yazdan Yazdanpanah (AP-HP, Hôpital 
Bichat, Paris), Jacques Reynes (CHU de Montpellier Gui de Chauliac, Montpellier), François Raffi and Clotilde Allavena (Hôpital Universitaire Hôtel Dieu, Nantes), Alissa Naqvi (Archet, Nice), Louis Bernard (Bretonneau, Tours), and Christian Chidiac (Croix Rousse, Lyon). Technical expertise was provided by Karima Hamdoud (AP-HP, Hôpital Bichat, Paris).

\section{References}

1. Kamara DA, Smith C, Ryom L, et al. Longitudinal analysis of the associations between antiretroviral therapy, viraemia and immunosuppression with lipid levels: the D:A: D study. Antivir Ther 2016;21:495-506.

2. Costagliola D. Demographics of HIV and aging. Curr Opin HIV AIDS 2014;9:294-301.

3. Calin R, Paris L, Simon A, et al. Dual raltegravir/etravirine combination in virologically suppressed HIV-1-infected patients on antiretroviral therapy. Antivir Ther 2012;17:1601-4.

4. Marcelin A-G, Flandre P, Descamps D, et al. Factors associated with virological response to etravirine in nonnucleoside reverse transcriptase inhibitor-experienced HIV-1-infected patients. Antimicrob Agents Chemother 2010;54:72-7.

5. Rockstroh JK, Lennox JL, Dejesus E, et al. Long-term treatment with raltegravir or efavirenz combined with tenofovir/ emtricitabine for treatment-naive human immunodeficiency virus-1-infected patients: 156-week results from STARTMRK. Clin Infect Dis Off Publ Infect Dis Soc Am 2011;53:807-16.

6. Fätkenheuer G, Duvivier C, Rieger A, et al. Lipid profiles for etravirine versus efavirenz in treatment-naive patients in the randomized, double-blind SENSE trial. J Antimicrob Chemother 2012;67:685-90.

7. Choquet M, Lê MP, Simon A, et al. Pharmacokinetic interactions between raltegravir and Non Nucleoside Reverse Transcriptase Inhibitors or Protease Inhibitors: a retrospective study from 2011 to 2012. 14th International Workshop on Clinical Pharmacology of HIV Therapy. 2013. Amsterdam, The Netherlands. Abstract P_06.

8. Ménard A, Solas C, Mokthari S, et al. Etravirine-raltegravir, a marked interaction in HIV-l-infected patients: about four cases. AIDS Lond Engl 2009;23:869-71.

9. Anderson MS, Kakuda TN, Hanley W, et al. Minimal pharmacokinetic interaction between the human immunodeficiency virus nonnucleoside reverse transcriptase inhibitor etravirine and the integrase inhibitor raltegravir in healthy subjects. Antimicrob Agents Chemother 2008;52:4228-32.

10. Drugs@FDA: FDA Approved Drug Products. Available from https://www.accessdata.fda.gov/scripts/cder/daf/index.cfm. Accessed December 2, 2018.

11. Katlama C, Reynes J, Assoumou L, et al. Raltegravir/etravirine as maintenance strategy in HIV-1-infected virologically suppressed individuals aged over 45 years on prior boosted protease inhibitor containing regimen: results at W48 of the ANRS163-ETRAL study. 9th IAS Conference on HIV Science (IAS 2017), July 2326, 2017, Paris. Abstract MOPEB0314. 2017.

12. Song I, Borland J, Min S, et al. Effects of etravirine alone and with ritonavir-boosted protease inhibitors on the pharmacokinetics of dolutegravir. Antimicrob Agents Chemother 2011;55: $3517-21$
13. Barau C, Furlan V, Yazdanpanah Y, et al. Characterization of binding of raltegravir to plasma proteins. Antimicrob Agents Chemother 2013;57:5147-50.

14. Nguyen A, Rossi S, Croteau D, et al. Etravirine in CSF is highly protein bound. J Antimicrob Chemother 2013;68:1161-8.

15. Jung BH, Rezk NL, Bridges AS, et al. Simultaneous determination of 17 antiretroviral drugs in human plasma for quantitative analysis with liquid chromatography-tandem mass spectrometry. Biomed Chromatogr BMC 2007;21:1095-104.

16. Acosta EP, Limoli KL, Trinh L, et al. Novel method to assess antiretroviral target trough concentrations using in vitro susceptibility data. Antimicrob Agents Chemother 2012;56:5938-45.

17. Markowitz M, Morales-Ramirez JO, Nguyen B-Y, et al. Antiretroviral activity, pharmacokinetics, and tolerability of MK-0518, a novel inhibitor of HIV-1 integrase, dosed as monotherapy for 10 days in treatment-naive HIV-1-infected individuals. J Acquir Immune Defic Syndr 1999;2006(43):50915.

18. Belkhir L, Seguin-Devaux C, Elens L, et al. Impact of UGTIAl polymorphisms on Raltegravir and its glucuronide plasma concentrations in a cohort of HIV-1 infected patients. Sci Rep 2018;8:7359.

19. Neely M, Decosterd L, Fayet A, et al. Pharmacokinetics and pharmacogenomics of once-daily raltegravir and atazanavir in healthy volunteers. Antimicrob Agents Chemother 2010;54:4619-25.

20. Zembruski NCL, Haefeli WE, Weiss J. Interaction potential of etravirine with drug transporters assessed in vitro. Antimicrob Agents Chemother 2011;55:1282-4.

21. Trezza CR, Kashuba ADM. Pharmacokinetics of antiretrovirals in genital secretions and anatomic sites of HIV transmission: implications for HIV prevention. Clin Pharmacokinet 2014;53: 611-24.

22. Tiraboschi JM, Niubo J, Ferrer E, et al. Etravirine concentrations in seminal plasma in HIV-infected patients. J Antimicrob Chemother 2013;68:184-7.

23. Antoniou T, Loutfy MR, Brunetta J, et al. Pharmacokinetics of raltegravir in the semen of HIV-infected men. Antivir Ther 2014;19:607-11.

24. Antoniou T, Hasan S, Loutfy MR, et al. Pharmacokinetics of maraviroc, raltegravir, darunavir, and etravirine in the semen of HIV-infected men. J Acquir Immune Defic Syndr 1999;2013 (62):e58-60.

25. Lê MP, Belarbi L, Chaix M-L, et al. Penetration and antiviral efficacy of total and unbound maraviroc, raltegravir and rilpivirine in both female and male genital fluids from HIV-positive patients receiving regimens containing these antiretrovirals. J Antimicrob Chemother 2017;72:3167-71.

26. Else LJ, Taylor S, Back DJ, et al. Pharmacokinetics of antiretroviral drugs in anatomical sanctuary sites: the male and female genital tract. Antivir Ther 2011;16:1149-67.

27. Hoque MT, Kis O, De Rosa MF, et al. Raltegravir permeability across blood-tissue barriers and the potential role of drug efflux transporters. Antimicrob Agents Chemother 2015;59: 2572-82.

28. Klein DM, Wright SH, Cherrington NJ. Xenobiotic transporter expression along the male genital tract. Reprod Toxicol 2014;47:1-8.

29. Reznicek J, Ceckova M, Tupova L, et al. Etravirine inhibits ABCG2 drug transporter and affects transplacental passage of tenofovir disoproxil fumarate. Placenta 2016;47:124-9. 